\title{
Sech a good operation. Pity we don't need it
}

What we do, and why we do it, matters more than how

F rom what is published in surgical journals and presented at surgical meetings, you might think that surgeons typically consider that the real changes currently happening in surgery relate to how we do things. Without doubt, this is of some importance. The development of minimally invasive therapies such as laparoscopic surgery, stereotactic surgery and endoscopic procedures has an important influence on the sharp end of surgical management. The new frontier in delivery of surgery is "robotic surgery" - perhaps better called "computerassisted surgery" - where surgeons can (as proponents claim) use robotic instruments to orchestrate an operation with more precise movements and better range of motion, assisted by three-dimensional video imaging. The advent of telementoring and telesurgery — perhaps even with the use of Google Glass - means that capabilities will exist to provide training and assistance, and improve surgical performance undertaken at remote locations. These technological advances are seen not just by the surgeon but also by the media and, by extension, the public, as an improvement in surgical care.

There are also other changes afoot in surgery - delivering improved work-life balance, as desired by many younger surgeons, encouraging and retaining female surgeons, rethinking surgical education and training, and engaging surgeons into hospital and professional management. But when it comes down to thinking about the current and future roles of surgery, how we do things really does not matter as much as what we do and why we do it.

Surgery in general is increasingly about doing less for many disorders that can be effectively managed in other ways. It is sometimes true that opportunities for new surgical disciplines arise to replace obsolete uses, creating a continuing demand for particular surgical subspecialties. For example, in the field of thoracic surgery - which almost died out with the advent of medical therapy for tuberculosis - lung cancer surgery and coronary artery bypass surgery filled a gap and kept thoracic surgeons busy.

But such substitution does not always occur. Hepatobiliary surgery for hydatid disease is all but gone. Gastric cancer is becoming increasingly uncommon thanks to the identification of the role of Helicobacter pylori and its medical treatment. Statins, stents and antiplatelet medications profoundly affect the demand for coronary artery bypass surgery. The use of immunomodulators has much diminished the need for surgery to manage inflammatory bowel disease. But, in the future, we may gain more medical understanding of many other conditions, obviating the need for surgery. For example, what if the cause of bowel cancer turns out to be an infection and can be treated by immunisation at a young age? What potential exists for other conditions to be prevented or treated non-surgically? The future role of surgery may very well be more likely to be determined by scientists than surgeons. The basic sciences are still where the big answers are to be found. Consequently, funding for notvery-sexy basic science research matters as much if not more than that for robotic, glass-eyed wizardry.

While the surgical management of some diseases has become less common, it has become more "fashionable" for some conditions to "go under the knife". Just as the advent of cardiac surgery filled an activity gap for thoracic surgery, the reframing of obesity as a surgical disease has created an opportunity, through bariatric procedures, for gastric surgeons otherwise displaced by the decline of gastric cancer and the need for surgical treatment of peptic ulcer.

Not only are the diseases we are operating on changing but so are our patient populations. Increased life expectancy has brought older patients with more comorbid conditions. Different diseases affect older people and appropriately tailored procedures are needed to obtain the best quality of life. ${ }^{1}$ However, despite the new challenges in this population of patients, surgery has much to offer them. Modern cataract surgery and joint replacement have substantially improved quality of life for many older patients.

What role does research in surgery have in the discipline's evolution? As alluded to above, research has yielded the evidence to better define the role of surgery in the management of many diseases, from the role of carotid endarterectomy in vascular disease to surgery for diverticular disease. Surgical research however remains problematic. Few high-quality randomised controlled trials in surgery have been conducted, ${ }^{2}$ either due to the logistic difficulty of such trials (only rarely supported financially as are drug trials) or due to the lack of equipoise in surgeons' interpretations of the available evidence - or perhaps it is just the surgical personality? ${ }^{3}$ As a result of these difficulties, many advances in surgery are better confirmed by the use of high-quality multicentre prospective audits, such as the international joint registries used to assess outcomes after different types of joint replacement.

Cost and safety are also important factors in driving change in surgery. The increasing percentage of gross domestic product spent on health across the Western world is unsustainable, ${ }^{4}$ and advances in surgery will accordingly need to come from the way we organise and

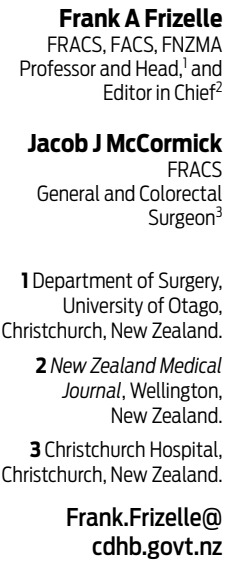

doi: 10.5694/mjal4.00662 
deliver it. With the increasing costs of surgical treatment, any funder must eventually demand lower costs achieved through more sound patient selection, the choice of procedure undertaken, how and where it is delivered and levels of remuneration for surgeons. ${ }^{5}$

The best way to predict the future of surgery is to look at the past, which tells us that most predictions of the future are wrong. Even though prediction is likely to be ultimately futile, we have some idea of where surgery is now and where it is headed. We can expect the continuing complementarity between medicine and surgery, even when some conditions fall out of the surgical scope and others come into view, and a greater awareness and involvement of research to support optimal care. We should expect that surgical therapies will become differently targeted, with more emphasis given to delivering greater benefit and efficiency, and that procedures will be adapted to new and different patient groups who stand to gain from surgery. Such changes can be hard to adopt and adapt to, but the surgical disciplines have done so before in order to undertake better care. The continuing challenges of "what to treat", "who to treat" and "how to treat" will remain a part of the satisfaction and engagement that surgeons have in performing their craft.

Competing interests: No relevant disclosures.

Provenance: Commissioned; externally peer reviewed.

1 Allardyce RA, Bagshaw PF, Frampton CM, et al; Australasian Laparoscopic Colon Cancer Study Group. Australasian Laparoscopic Colon Cancer Study shows that elderly patients may benefit from lower postoperative complication rates following laparoscopic versus open resection. Br J Surg 2010; 97: 86-91.

2 Bagshaw PF, Allardyce RA, Frampton CM, et al; Australasian Laparoscopic Colon Cancer Study Group. Long-term outcomes of the Australasian randomized clinical trial comparing laparoscopic and conventional open surgical treatments for colon cancer: the Australasian Laparoscopic Colon Cancer Study trial. Ann Surg 2012; 256: 915-919.

3 Allardyce RA, Bagshaw PF, Frampton CM, et al. Ethical issues with the disclosure of surgical trial short-term data. ANZ J Surg 2011; 81: 125-131.

4 Frizelle FA. Health expenditure and the ageing population. N Z Med J 2005; 118: U1251.

5 Frizelle FA. Resourcing for the growing burden of elderly patients with cancer. ANZ J Surg 2008; 78: 428-429. 